\title{
Knowledge, attitude, and practices toward chronic kidney disease among care providers in Jimma town:cross-sectional study
}

Amare Desalegn Wolide ${ }^{1 *} \mathbb{D}$, Kabaye Kumela ${ }^{2}$, Fantu Kerga ${ }^{2}$, Serkadis Debalke ${ }^{3}$, Meskerem Seboka ${ }^{4}$, Birtukan Edilu ${ }^{5}$, Fanta Gashe ${ }^{2}$ and Eshetu Mulisa Bobassa ${ }^{2}$

\begin{abstract}
Background: Chronic kidney disease (CKD) is a common and growing health problem that requires adequate Knowledge by health care providers to reduce the progress of the disease. Thus, this study aimed to assess the care provider's Knowledge, attitude, and practices toward CKD.

Method: A cross-sectional study conducted among 326 care providers at Jimma University Specialized hospital and three medium to higher clinics found in Jimma Town. Collected data entered into Epi-Data version 3.1 and exported to SPSS version 21 for windows for data analysis. Descriptive statistics and generalized linear modal used to analyze the data.

Result: The mean age and service year of the participants were $29.68( \pm 4.877)$ and $4.28( \pm 4.561)$, respectively. The overall weighted Knowledge, attitude, and practice score of the study participant were 9.0971(8.77, 9.42), 2.53(2.4, 2.65), $10.14(9.94,10.33)$ respectively. Over half of the care providers had the awareness to use eGFR to assess kidney function and patient referral to Nephrologists. Also, many care providers knew the five-stage of CKD and the risk factors of CKD, such as diabetes, long-term alcohol consumption, anemia, and cardiovascular disorders, respectively. Care providers had an understanding of late detection, and referral of CKD would increase kidney disease complications. Besides, 275(84.4\%) of them are worried about treatment costs related to CKD. Over half of the care providers, 238(73.0\%), believed that the Ethiopian ministry of health gave less attention to the problem. Furthermore, 234(71.8\%) are interested in studying more on CKD management. Majority 256(78.5\%), very likely or likely refer the patient to senior physician and Nephrologist.
\end{abstract}

Conclusion: Care providers showed enough Knowledge, a favorable attitude, and practice toward CKD.

Keywords: Care providers, Chronic kidney disease, Kidney disease

\footnotetext{
* Correspondence: amaju2002@yahoo.com

'Department of Medical Physiology, Institute of Health Sciences, Jimma University, 378 Jimma, Ethiopia

Full list of author information is available at the end of the article
}

(c) The Author(s). 2020 Open Access This article is licensed under a Creative Commons Attribution 4.0 International License, which permits use, sharing, adaptation, distribution and reproduction in any medium or format, as long as you give appropriate credit to the original author(s) and the source, provide a link to the Creative Commons licence, and indicate if changes were made. The images or other third party material in this article are included in the article's Creative Commons licence, unless indicated otherwise in a credit line to the material. If material is not included in the article's Creative Commons licence and your intended use is not permitted by statutory regulation or exceeds the permitted use, you will need to obtain permission directly from the copyright holder. To view a copy of this licence, visit http://creativecommons.org/licenses/by/4.0/ The Creative Commons Public Domain Dedication waiver (http://creativecommons.org/publicdomain/zero/1.0/) applies to the data made available in this article, unless otherwise stated in a credit line to the data. 


\section{Background}

Chronic kidney disease (CKD) is a worldwide epidemic health problem of increasing prevalence and costing an enormous burden on healthcare systems [1-3]. The global increase in CKD needs a well-organized preventive strategy mainly by detecting the risk factors [4-7]. According to the American Heart Association (AHA) statement released in 2013, CKD mentioned as a significant risk factor for coronary disease [8-12]. Earlier-stage CKD can also lead to several complications related to anemia and bone mineral metabolism disorders [13]. Despite these known adverse consequences of CKD, the vast majority of the people remain unaware of the disease $[14,15]$. Kidney disease (KD) can be diagnosed with simple laboratory procedures. However, people's practice toward testing (screening) themselves to know the status of CKD is exceptionally very low.

Further, awareness of CKD remains unacceptably low among care providers [16-20]. Earlier recognition of CKD by nephrologists can slow the progression of the disease [21-25]. However, the late evaluation of CKD patients by nephrologists would increase renal failure [26-29]. A non-nephrologist mostly sees most patients with CKD seeking treatment in tertiary hospitals. The Nephrologist has relatively sufficient awareness related to CKD diagnosis than non-nephrologist $[14,30]$. In Ethiopia, because of the poor infrastructure, inadequate laboratory facility, and shortage of human resources in the area, physicians frequently use urine and serum creatinine as a means of CKD diagnosis and its severity. However, serum creatinine may not indeed indicate the different stage of CKD, because creatinine level might increases in the blood after high protein ingestions, intense exercise and after taking some drugs such as Cimetidine, Trimethoprim, Pyrimethamine, Salicylates, Phenacemide, Corticosteroids, and Vitamin D derivatives [31]. Increasing evidence indicates that the CKD burden is growing in developing countries because of increased risk factors such as high blood pressure and diabetes mellitus [32-34]. According to the unpublished study, renal disease covers $1.2-6 \%$ of adult hospital medical admissions in Ethiopia. Chronic glomerulonephritis, diabetes, and hypertension are the leading causes of chronic kidney disease in Ethiopia.

Additionally, besides the low number of nephrologists in the country, a deficient level of awareness about kidney diseases, risk factors, diagnosis, and management among care providers is believed to be very low. Thus, this study proposed to see the level of care providers' Knowledge, attitude, and practices (KAP) toward CKD. Farther more, the investigators believe that the study will bring change in the area by identifying gaps for future direction and better patient approach regarding CKD management.

\section{Methods}

\section{Study design and study setting}

A cross-sectional study was conducted at Jimma University Specialized Hospital (JUSH) and three leading higher private clinics, Jimma town, Ethiopia from February 25, 2018, to June 21, 2018. The University hospital is the only specialized referral hospital in the Southwestern part of Ethiopia, serving approximately 12 million inhabitants.

\section{Sample size and sampling method}

The sample size was determined based on the single population proportion formula using $\mathrm{Z} 2 \times \mathrm{p} \times \mathrm{q} / \mathrm{d} 2$ with the assumption of the prevalence of $50 \%$ for Knowledge, attitudes, and practices (KAP) of chronic kidney disease, a $95 \%$ confidence interval and a margin error of $5 \%$. Finally, adding a $10 \%$ non-response rate, the total sample size was 422. Study subjects recruited using a nonprobability purposive sampling method.

\section{Inclusion and exclusion criteria}

The study covered a wide variety of care provider professionals found in the internal medicine wards, Pediatrics wards, gynecology and obstetrics ward, surgery ward, and many others. General practitioner, resident doctors, specialist doctors, and other health sciences professionals were eligible for the study. Then, consenting professionals received questions on Knowledge, attitude, and practice on chronic kidney diseases.

\section{Method of data collection}

We developed a questionnaire after an extensive literature review to include items assessing Knowledge, attitudes, and practices (KAP) on CKD. Experts in the area evaluated issues difficultly and discrimination in the survey. We did the pre-test among volunteer health care providers to figure out problems in the questionnaire. The data collectors and supervisors discussed the study thoroughly among themselves before data collection. Cronbach's alpha $(>0.62)$ used to examine internal consistency and reliability. The questionnaire divided into two sections with the first section comprising the socio-demographic future, service year, and type of area (specialty) that the health care providers are currently working. The later section contains KAP questions to assess professional KAP of chronic kidney disease. The final version administered as part of this study consisted of 25 items divided into three conceptual domains: Knowledge, attitudes, and practices for kidney disease. We designed the knowledge domain to test the understanding of care providers on the etiologies, diagnosis, and treatment of kidney disease as well as the normal function of the kidneys. Fourteen questions in a fourpoint response scale ("Yes", "No," "Do Not Know," "Unsure") prepared to assess Knowledge. Similarly, four 
questions with a five-point categorical response scale ("Strongly Agree", "Agree", "Not sure", "Disagree", "Strongly disagree") prepared to measure care provides attitudes. Finally, the practice domain comprised seven items with a four-point Likert-scale ("Very Unlikely", "Unlikely", "Likely", "Very Likely") to evaluate care providers' practice.

\section{Statistical analysis}

Data analysis performed using the International Business Machines Corporation-Statistical Package for Social Sciences program version 21 (IBM-SPSS Statistics 21). Results of the continuous variables expressed as means \pm Standard Deviation (SD), whereas frequencies (percentages) used to display the result of categorical variables. The normality of the continuous data viewed by using the Kolmogorov-Smirnov test and the data distribution was normal. Generalized linear model used to analyze Knowledge score and crude associations. A dummy coding of 0 and 1 used to enter the nominal independent variables into the regression model. The possible presence of multicollinearity between independent variables was explored based on the variance inflation factor (VIF). Internal consistency of all types of questions and their subscales assessed using Cronbach's alpha. All $P$ values considered significant at $<0.05$. For the knowledge domain, we calculated a composite score (range: $0-14$ ). To do so, we first scored each item as correct (1) or incorrect (0) with the responses 'Do Not Know' and 'Unsure' treated as incorrect. We then obtained the sum of the 14 scored items. For the attitudes domain, each item scored as "Strongly agree" (1), 'Agree' (1) or 'Not sure' (0), 'Disagree' (0), and 'Strongly disagree' (0). For the practices domain, each item scored as 'Very unlikely' (1), 'Unlikely' (1), 'Likely' (0), or 'Very likely' (0). The study participants who scored 70\% and above in the overall weighted mean score considered as having adequate Knowledge, positive attitude and good practices.

\section{Ethical considerations}

The Ethical Review Board of Jimma University approved the study with the reference number IHRPGD/3019/ 2019. All ethical requirements stringently ensured to keep participants confidentiality.

\section{Result}

\section{Participant characteristics}

A total of 326 health care professionals involved and the majority of the participants were Male 227(69.6\%) and general practitioners $96(29.4 \%)$. The mean age and service year of the participants were $29.68( \pm 4.877)$ and $4.28( \pm 4.561)$, respectively (Table 1$)$.

\section{Knowledge}

The overall weighted Knowledge, attitude, and practice score of the participant on CKD were 9.0971(8.77, 9.42), 2.53(2.4, 2.65), and 10.14(9.94, 10.33). Male participants had higher mean Knowledge $(9.54(9.17,9.91))$ than females. Residents $10.1(9.49,10.65)$ had a higher knowledge score than other professionals. Also, male sex $0.875(0.204,1.547)$ residents $1.84(0.979,2.694)$ and specialist $1.72(0.802,2.646)$ showed significant liner associations with the crude knowledge score of chronic kidney disease. The majority of the respondents, 191 (58.6\%) knew that eGFR (estimated Glomerular Filtration Rate) is a better way to assess the severity of kidney disease. Also, 180(55.2\%) of the

Table 1 Univariable Linear Regression Models Among Care Providers in Jimma, $2018(n=326)$

\begin{tabular}{|c|c|c|c|c|}
\hline Variable & Frequency (\%) & Mean $( \pm)$ & $\begin{array}{l}\text { Score } \\
\text { B }(95 \% \text { CI) }\end{array}$ & Mean Score $(95 \% \mathrm{Cl})$ \\
\hline \multicolumn{5}{|l|}{ Sex } \\
\hline Male & $227(69.6 \%)$ & - & $0.875(0.204,1.547)$ & $9.54(9.17,9.91)$ \\
\hline Female & $99(30.4 \%)$ & - & r & $8.66(8.11,9.22)$ \\
\hline Age & - & $29.68( \pm 4.877)$ & & \\
\hline Service year & - & $4.28( \pm 4.561)$ & & \\
\hline \multicolumn{5}{|l|}{ Area of specialization } \\
\hline General Practitioner & $96(29.4 \%)$ & - & $0.595(-0.257,1.447)$ & $8.82(8.262,9.363)$ \\
\hline Residents Doctors & $93(28.5 \%)$ & - & $1.84(0.979,2.694)^{*}$ & $10.1(9.49,10.65)$ \\
\hline Specialist Doctors & $68(20.9 \%)$ & - & $1.72(0.802,2.646)^{*}$ & $9.94(9.3,10.59)$ \\
\hline Other Health Sciences $^{a}$ & $69(21.2 \%)$ & - & r & $8.22(7.56,8.86)$ \\
\hline Overall weighted Knowledge & & & & $9.0971(8.77,9.42)$ \\
\hline Overall weighted Attitude & & & & $2.53(2.4,2.65)$ \\
\hline Overall weighted Practice & & & & $10.14(9.94,10.33)$ \\
\hline
\end{tabular}

Key: $B$ Unstandardized Coefficients, $C$ C Confidence Interval, $r$ Reference Group

* = Significant association $(p<0.05)$

${ }^{a}$ Other Health Sciences $=$ Nurse, Anesthesia, Clinical Pharmacist and laboratory technologist 
participants had a knowledge that eGFR helped in referral to a nephrologist (Q2). The highest proportion of the study participants, 202(62.0\%), do not think an age-related reduction of eGFR with no kidney disease leads to low eGFR as far as serum creatinine is in the normal range (Q3). Farther more, the majority of the participants also declared that they did not know about the standard treatment protocol and the Modification of Diet in Renal Disease (MDRD) formula to asses kidney function in patients (Q4). Almost all care providers, 298(91.4\%), had the understanding that diabetes and hypertension are possible risk factors of CKD. Furthermore, they knew that long-term alcohol consumption and anemia are the potential risk factors of CKD (Table 2).

\section{Attitude}

The majority of the study participants, 275(84.4\%), agreed that they worry about treatment cost for CKD (Q1). To the same extent, 219(67.2\%) of participants also believed that CKD is a significant public health problem in Ethiopia (Q2), and 238(73.0\%) of the participants disagree that the ministry of health is working hard in the prevention of the disease (Q3). Furthermore, 234(71.8\%) participants agreed that they need more education on CKD and eGFR (Q4) (Table 3).

\section{Practices}

The majority of the participants 256(78.5\%), Very likely or likely refer patients with CKD to senior physician and

Table 2 Knowledge on stratified by care providers in Jimma Town, $2018(n=326)$

\begin{tabular}{|c|c|c|c|c|c|c|}
\hline \multirow[t]{2}{*}{ Knowledge Domain Survey Items } & & \multicolumn{4}{|c|}{ Health Care Professional } & \multirow{2}{*}{$\begin{array}{l}\text { Total } \\
\boldsymbol{n}=326 \\
(100 \%)\end{array}$} \\
\hline & & $\begin{array}{l}\mathrm{GP} \\
\boldsymbol{n}=96(29.4 \%)\end{array}$ & $\begin{array}{l}\text { Resident } \\
\boldsymbol{n}=93(28.5 \%)\end{array}$ & $\begin{array}{l}\text { Specialist } \\
\boldsymbol{n}=68(20.9 \%)\end{array}$ & $\begin{array}{l}\mathrm{OHS} \\
\boldsymbol{n}=69(21.2 \%)\end{array}$ & \\
\hline \multirow{2}{*}{$\begin{array}{l}\text { Q1. Is eGFR a better way... severity of } \\
\text { creatinine alone? }\end{array}$} & 0 & $41(12.6 \%)$ & $27(8.3 \%)$ & $25(7.7 \%)$ & $42(12.9 \%)$ & $135(41.4 \%)$ \\
\hline & 1 & $55(16.9 \%)$ & $66(20.2 \%)$ & $43(13.2 \%)$ & $27(8.3 \%)$ & $191(58.6 \%)$ \\
\hline \multirow{2}{*}{$\begin{array}{l}\text { Q2. Has eGFR helped in referral..... } \\
\text { Significantly, elevated? }\end{array}$} & 0 & $35(10.7 \%)$ & $51(15.6 \%)$ & $29(8.9 \%)$ & $31(9.5 \%)$ & $146(44.8 \%)$ \\
\hline & 1 & $61(18.7 \%)$ & $42(12.9 \%)$ & $39(12.0 \%)$ & $38(11.7 \%)$ & $180(55.2 \%)$ \\
\hline \multirow{2}{*}{$\begin{array}{l}\text { Q3. Can age related reduction... Urine } \\
\text { analysis? }\end{array}$} & 0 & $55(16.9 \%)$ & $50(15.3 \%)$ & $40(12.3 \%)$ & $57(17.5 \%)$ & $202(62.0 \%)$ \\
\hline & 1 & $41(12.6 \%)$ & 43(13.2\%) & $28(8.6 \%)$ & $12(3.7 \%)$ & 124(38.0\%) \\
\hline \multirow{2}{*}{$\begin{array}{l}\text { Q4. Are you aware of Modification of } \\
\text { diet in Renal Disease formula? }\end{array}$} & 0 & $36(11.0 \%)$ & $45(13.8 \%)$ & $35(10.7 \%)$ & $14(4.3 \%)$ & $130(39.9 \%)$ \\
\hline & 1 & $60(18.4 \%)$ & $48(14.7 \%)$ & $33(10.1 \%)$ & $55(16.9 \%)$ & $196(60.1 \%)$ \\
\hline \multirow{2}{*}{$\begin{array}{l}\text { Q5. Kidney problem can be easily } \\
\text { detected ....urine color } \\
\text { or smell? }\end{array}$} & 0 & $63(19.3 \%)$ & $64(19.6 \%)$ & $37(11.3 \%)$ & $33(10.1 \%)$ & $197(60.4 \%)$ \\
\hline & 1 & $33(10.1 \%)$ & $29(8.9 \%)$ & $31(9.5 \%)$ & $36(11.0 \%)$ & $129(39.6 \%)$ \\
\hline \multirow{2}{*}{$\begin{array}{l}\text { Q6. Are you aware the five stages } \\
\text { of CKD? }\end{array}$} & 0 & $39(12.0 \%)$ & $16(4.9 \%)$ & $11(3.4 \%)$ & $45(13.8 \%)$ & $111(34.0 \%)$ \\
\hline & 1 & $57(17.5 \%)$ & $77(23.6 \%)$ & $57(17.5 \%)$ & $24(7.4 \%)$ & $215(66.0 \%)$ \\
\hline \multirow[t]{2}{*}{ Q7. DM and HBP might cause CKD. } & 0 & $11(3.4 \%)$ & $1(0.3 \%)$ & $4(1.2 \%)$ & $12(3.7 \%)$ & $28(8.6 \%)$ \\
\hline & 1 & $85(26.1 \%)$ & $92(28.2 \%)$ & $64(19.6 \%)$ & $57(17.5 \%)$ & $298(91.4 \%)$ \\
\hline \multirow{2}{*}{$\begin{array}{l}\text { Q8. Long-term Alcohol consumption } \\
\text { might cause CKD? }\end{array}$} & 0 & $39(12.0 \%)$ & $19(5.8 \%)$ & $10(3.1 \%)$ & $9(2.8 \%)$ & $77(23.6 \%)$ \\
\hline & 1 & $57(17.5 \%)$ & $74(22.7 \%)$ & $58(17.8 \%)$ & $60(18.4 \%)$ & $249(76.4 \%)$ \\
\hline \multirow{2}{*}{$\begin{array}{l}\text { Q9. Anemia and cardiovascular disorders } \\
\text { are risky for CKD? }\end{array}$} & 0 & $11(3.4 \%)$ & $3(0.9 \%)$ & $7(2.1 \%)$ & $20(6.1 \%)$ & $41(12.6 \%)$ \\
\hline & 1 & $85(26.1 \%)$ & $90(27.6 \%)$ & $61(18.7 \%)$ & $49(15.0 \%)$ & $285(87.4 \%)$ \\
\hline \multirow{2}{*}{$\begin{array}{l}\text { Q10.Early detection of chronic kidney } \\
\text { disease saves health care cost }\end{array}$} & 0 & $20(6.1 \%)$ & $8(2.5 \%)$ & $9(2.8 \%)$ & $9(2.8 \%)$ & $46(14.1 \%)$ \\
\hline & 1 & $76(23.3 \%)$ & $85(26.1 \%)$ & $59(18.1 \%)$ & $60(18.4 \%)$ & $280(85.9 \%)$ \\
\hline \multirow{2}{*}{$\begin{array}{l}\text { Q11. Late referral to a Nephrologists } \\
\text { causes..? }\end{array}$} & 0 & 19(5.8\%) & $9(2.8 \%)$ & $7(2.1 \%)$ & $22(6.7 \%)$ & $57(17.5 \%)$ \\
\hline & 1 & $77(23.6 \%)$ & $84(25.8 \%)$ & $61(18.7 \%)$ & $47(14.4 \%)$ & $269(82.5 \%)$ \\
\hline \multirow{2}{*}{$\begin{array}{l}\text { Q12. Do you know any standard } \\
\text { treatment guideline of CKD? }\end{array}$} & 0 & $37(11.3 \%)$ & $40(12.3 \%)$ & $35(10.7 \%)$ & $17(5.2 \%)$ & $129(39.6 \%)$ \\
\hline & 1 & $59(18.1 \%)$ & $53(16.3 \%)$ & $33(10.1 \%)$ & $52(16.0 \%)$ & $197(60.4 \%)$ \\
\hline \multirow[t]{2}{*}{ Q13. B-Blockers.... and ACEls? } & 0 & $51(15.6 \%)$ & $40(12.3 \%)$ & $30(9.2 \%)$ & $15(4.6 \%)$ & $136(41.7 \%)$ \\
\hline & 1 & $45(13.8 \%)$ & $53(16.3 \%)$ & $38(11.7 \%)$ & $54(16.6 \%)$ & $190(58.3 \%)$ \\
\hline \multirow{2}{*}{$\begin{array}{l}\text { Q14. Dialysis and organ } \\
\text { transplantation? }\end{array}$} & 0 & $9(2.8 \%)$ & $3(0.9 \%)$ & $9(2.8 \%)$ & $8(2.5 \%)$ & 29(8.9\%) \\
\hline & 1 & $87(26.7 \%)$ & $90(27.6 \%)$ & $59(18.1 \%)$ & $61(18.7 \%)$ & $297(91.1 \%)$ \\
\hline
\end{tabular}

Key: 0-Incorrect (No, Dont know, Unsure), 1-Correct (Yes)

GP General Practitioner, OHS Other Health Sciences, eGFR estimated Glomerular filtration rate, CKD Chronic Kidney Diseases, DM Diabetes Mellitus, ACEI Angiotensin-converting enzyme (ACE) inhibitors 
Table 3 Attitude on Chronic Kidney Disease Stratified by Care Providers in Jimma Town, 2018 ( $n=326)$

\begin{tabular}{|c|c|c|c|c|c|c|}
\hline \multirow[t]{2}{*}{ Attitude Domain Survey Items } & & \multicolumn{4}{|c|}{ Health Care Professional } & \multirow{2}{*}{$\begin{array}{l}\text { Total } \\
\boldsymbol{n}=326 \\
(100 \%)\end{array}$} \\
\hline & & $\begin{array}{l}\mathrm{GP} \\
\boldsymbol{n}=96(29.4 \%)\end{array}$ & $\begin{array}{l}\text { Resident } \\
\boldsymbol{n}=93(28.5 \%)\end{array}$ & $\begin{array}{l}\text { Specialist } \\
\boldsymbol{n}=68(20.9 \%)\end{array}$ & $\begin{array}{l}\text { OHS } \\
\boldsymbol{n}=69(21.2 \%)\end{array}$ & \\
\hline \multirow{2}{*}{$\begin{array}{l}\text { Q1. I often worry about treatment } \\
\text { cost for CKD for patients? }\end{array}$} & 0 & $83(25.5 \%)$ & $86(26.4 \%)$ & $49(15.0 \%)$ & $57(17.5 \%)$ & $275(84.4 \%)$ \\
\hline & 1 & 13(16.9\%) & $7(20.2 \%)$ & 19(13.2\%) & $12(8.3 \%)$ & $51(15.6 \%)$ \\
\hline \multirow{2}{*}{$\begin{array}{l}\text { Q2.Kidney disease is a major public } \\
\text { health problem in Ethiopia? }\end{array}$} & 0 & $62(19.0 \%)$ & $65(19.9 \%)$ & $39(12.0 \%)$ & $53(16.3 \%)$ & $219(67.2 \%)$ \\
\hline & 1 & $34(10.4 \%)$ & $28(8.6 \%)$ & 29(8.9\%) & $16(4.9 \%)$ & $107(32.8 \%)$ \\
\hline \multirow{2}{*}{$\begin{array}{l}\text { Q3.Ethiopian Ministry of Health } \\
\text { gives adequate attention? }\end{array}$} & 0 & $24(7.4 \%)$ & $20(6.1 \%)$ & $20(6.1 \%)$ & $24(7.4 \%)$ & $88(27.0 \%)$ \\
\hline & 1 & $72(22.1 \%)$ & $73(22.4 \%)$ & $48(14.7 \%)$ & $45(13.8 \%)$ & $238(73.0 \%)$ \\
\hline \multirow{2}{*}{$\begin{array}{l}\text { Q4.Do you need more education } \\
\text { on CKD and eGFR? }\end{array}$} & 0 & $65(19.9 \%)$ & $66(20.2 \%)$ & $50(15.3 \%)$ & $53(16.3 \%)$ & $234(71.8 \%)$ \\
\hline & 1 & $31(9.5 \%)$ & $27(8.3 \%)$ & $18(5.5 \%)$ & $16(4.9 \%)$ & $92(28.2 \%)$ \\
\hline
\end{tabular}

Key: 0- Agree and strongly agree

1-Unsure, Disagree, strongly disagree

GP General Practitioner, OHS Other Health Sciences, eGFR estimated Glomerular filtration rate, CKD Chronic Kidney Diseases, ACEI Angiotensin-converting enzyme (ACE) inhibitors

Nephrologist (Q1). Similarly, 280(85.9\%) and 245(75.2\%) of participants Very Unlikely and Unlikely refer patients to get care from a traditional healer $(\mathrm{Q} 2)$ and treat themselves at home $(\mathrm{Q} 3)$, respectively. Many participants, 260(79.8\%), responded Very Unlikely or Unlikely to prepare weekly/monthly meetings to discuss issues related with CKD (Q7) (Table 4).

\section{Discussion}

This study has assessed the care providers' Knowledge, attitude, and practices toward chronic kidney disease in
Jimma town, Jimma Ethiopia. Overall, study participants involved in this study had enough Knowledge, favorable opinion, and practice toward CKD. Participants knew the essential functions of the kidney, risk factors, and diagnosis of CKD. Renal diseases requires a compressive management of glomerular filtration rate, and need to monitor our blood glucose and blood pressure level quite regularly. The Modification of Diet in Renal Disease (MDRD) is a multicenter clinical trial study designed to assess acceptance, safety, and efficacy of restricted protein and phosphorus diets in patients with

Table 4 Practice on Chronic Kidney Disease Stratified by Care Providers in Jimma Town, 2018 ( $n=326)$

\begin{tabular}{|c|c|c|c|c|c|c|}
\hline \multirow[t]{2}{*}{ Practice Domain Survey Items } & & \multicolumn{4}{|c|}{ Health Care Professional } & \multirow{2}{*}{$\begin{array}{l}\text { Total } \\
\boldsymbol{n}=326 \\
(100 \%)\end{array}$} \\
\hline & & $\begin{array}{l}\mathrm{GP} \\
\boldsymbol{n}=96(29.4 \%)\end{array}$ & $\begin{array}{l}\text { Resident } \\
\boldsymbol{n}=93(28.5 \%)\end{array}$ & $\begin{array}{l}\text { Specialist } \\
\boldsymbol{n}=68(20.9 \%)\end{array}$ & $\mathrm{OHS} \boldsymbol{n}=69(21.2 \%)$ & \\
\hline \multirow{2}{*}{$\begin{array}{l}\text { Q1. How likely would you refer } \\
\text { patients to Nephrologists? }\end{array}$} & 0 & $14(4.3 \%)$ & $16(4.9 \%)$ & $28(8.6 \%)$ & $12(3.7 \%)$ & $70(21.5 \%)$ \\
\hline & 1 & $82(25.2 \%)$ & $77(23.6 \%)$ & $40(12.3 \%)$ & $57(17.5 \%)$ & $256(78.5 \%)$ \\
\hline \multirow{2}{*}{$\begin{array}{l}\text { Q2. How likely would you.. } \\
\text { Traditional healer? }\end{array}$} & 0 & $82(25.2 \%)$ & $79(24.2 \%)$ & $63(19.3 \%)$ & $56(17.2 \%)$ & $280(85.9 \%)$ \\
\hline & 1 & $14(4.3 \%)$ & $14(4.3 \%)$ & $5(1.5 \%)$ & $13(4.0 \%)$ & $46(14.1 \%)$ \\
\hline \multirow{2}{*}{$\begin{array}{l}\text { Q3. How likely would you ...to } \\
\text { treat themselves at home? }\end{array}$} & 0 & $58(17.8 \%)$ & $78(23.9 \%)$ & $57(17.5 \%)$ & $52(16.0 \%)$ & $245(75.2 \%)$ \\
\hline & 1 & $38(11.7 \%)$ & $15(4.6 \%)$ & $11(3.4 \%)$ & $17(5.2 \%)$ & $81(24.8 \%)$ \\
\hline \multirow{2}{*}{$\begin{array}{l}\text { Q4. How likely you use } \\
\text { information from text books or } \\
\text { social media? }\end{array}$} & 0 & $38(11.7 \%)$ & $45(13.8 \%)$ & $50(15.3 \%)$ & $29(8.9 \%)$ & $162(49.7 \%)$ \\
\hline & 1 & $58(17.8 \%)$ & $48(14.7 \%)$ & $18(5.5 \%)$ & $40(12.3 \%)$ & $164(50.3 \%)$ \\
\hline \multirow{2}{*}{$\begin{array}{l}\text { Q5. Have you ever told your } \\
\text { patient preventing kidney disease? }\end{array}$} & 0 & $24(7.4 \%)$ & $27(8.3 \%)$ & $32(9.8 \%)$ & $14(4.3 \%)$ & $97(29.8 \%)$ \\
\hline & 1 & $72(22.1 \%)$ & $66(20.2 \%)$ & $36(11.0 \%)$ & $55(16.9 \%)$ & $229(70.2 \%)$ \\
\hline \multirow{2}{*}{$\begin{array}{l}\text { Q6. Does your health facility... } \\
\text { regarding kidney disease? }\end{array}$} & 0 & $74(22.7 \%)$ & $74(22.7 \%)$ & $58(17.8 \%)$ & $54(16.6 \%)$ & $260(79.8 \%)$ \\
\hline & 1 & $22(6.7 \%)$ & 19(5.8\%) & $10(3.1 \%)$ & $15(4.6 \%)$ & $66(20.2 \%)$ \\
\hline \multirow{2}{*}{$\begin{array}{l}\text { Q7. How likely you use routine } \\
\text { urine proteins as diagnosis of CKD? }\end{array}$} & 0 & $25(7.7 \%)$ & $25(7.7 \%)$ & 28(8.6\%) & 25(7.7\%) & $103(31.6 \%)$ \\
\hline & 1 & $71(21.8 \%)$ & $68(20.9 \%)$ & $40(12.3 \%)$ & $44(13.5 \%)$ & $223(68.4 \%)$ \\
\hline
\end{tabular}

Key:

0 . Very Unlikely and Unlikely

1. Very Likely and Likely

GP General Practitioner, OHS Other Health Sciences, eGFR estimated Glomerular filtration rate, CKD Chronic Kidney Diseases, ACEI Angiotensin-converting enzyme (ACE) inhibitors 
progressive renal disease [33]. However, in our study, over half of participants had no the understanding about the MDRD equation. In many developing countries, it is hard to get new and advanced medical information quickly due to a lack of resources to access online and printed guidelines. Besides, no enough training available for care provides to update their Knowledge and skills regularly. A similar report has seen from a Tertiary Care Hospital in Pakistan [34, 35]. Our study participants often prescribe drugs such as $\beta$ Blockers, Thiazide Diuretics, and Angiotensin Converting Enzyme (ACE) inhibitors to patients with CKD. Rubeen et al. 2009 and many others [32, 36-43] have reported the same finding. Dialysis and kidney transplant are the other treatment options for patients with ESKD. However, accessibility and affordability for dialysis and transplant treatment is a massive problem in Ethiopia. On top of that, getting the right organ and organ donors in Ethiopia is still a problem. Besides, the country has a limited nephrologist who can perform this task [44].

In the current study, care providers showed a keen interest in learning about eGFR and kidney disease. Besides, the majority of the study participants felt that kidney problem in Ethiopia is a public health problem that the minister of health gave less attention to the prevention and treatment of CKD. The reason might be a lack of human resources and infrastructure. Resources is one of the vital element to decrease the spread of diseases and improve health services for patients. Kidney disease is now a health problem that kills a thousand individuals without seeing doctors [45]. To mitigate the problem, the ministry of health needs to make a tremendous effort on the health infrastructure and capacity building in the area. As far as practice parameters are concerned, we identified that the majority of the study participants very likely or likely refer patients to Nephrologists. Furthermore, care providers confirm that they had no regular or periodic meeting to discuss kidney disease. However, they often had a talk with their patients about kidney diseases and preventive measures.

\section{Limitations}

We understand that the current study might suffer from the usual "egg or chicken" dilemma, as the cross-sectional design did not allow for a conclusion about the direction of casualty between the response variable (KAP) and predictor variables. The second limitation of the study may be study subject selection bias and recall bias.

\section{Conclusion}

The overall weighted knowledge score of the participant on CKD was 9.0971 $(8.77,9.42)$, which is above a moderate level. Care providers should update themselves on the current advancement of sciences related to CKD treatment and management. Clinical departments should prepare regular meetings to discuss issues associated with CKD. Furthermore, patient referral to the appropriate care unite should be encouraged. The ministry of health should give adequate attention to the prevention work, as many care providers agreed that CKD is a public health problem in Ethiopia. Thus, health ministry and other concerned bodies should update the status of CKD in the country and should get the attention it deserves on treatment and prevention options. Care providers should also update themselves on the current advancement of sciences related to CKD treatment and management. Clinical departments also should prepare regular meetings to discuss issues associated with CKD.

\section{Supplementary information}

Supplementary information accompanies this paper at https://doi.org/10. 1186/s12889-020-09192-5.

Additional file 1. Data collection tool.

\section{Abbreviations}

ACE: Angiotensin Converting Enzyme, A; HA: American Heart Association; CKD: Chronic Kidney Diseases; eGFR: estimated Glomerular Filtration Rate; ESRD: End Stage Renal Disease; JUSH: Jimma University Specialized Hospital; KAP: Knowledge, Attitude, and Practices; KD: Kidney Diseases;

MDRD: Modification of Diet in Renal Disease; SD: Standard Deviation; SPSS: Statistical Package for Social Sciences; VIF: Variance Inflation Factor

\section{Acknowledgments}

The authors would like to acknowledge study participants, data collectors, and Jimma University stuffs. Furthermore, we would like to extend our acknowledgments to Jimma University, Institute of health sciences, for financial support. The funders had no role in the design, data collection, or analysis of this study and were not involved in the interpretation of data or in writing the manuscript.

\section{Authors' contributions}

ADW and EMB synthesized the idea and design of the study. ADW, EMB, KK, FK, $\mathrm{SD}, \mathrm{MS}, \mathrm{BE}$, and FG involved in the data collection. ADW analyzed the data and prepared the manuscript. All authors read and approved the final manuscript.

\section{Funding}

The study was supported by Jimma University, Institute of Health Sciences, with reference number IHRPGD/3019/2019.

\section{Availability of data and materials}

The datasets used and analyzed during the current study available from the corresponding author on reasonable request.

\section{Ethics approval and consent to participate}

The Institutional Review Board of Jimma University approved this study. All participants provided written consent to participate in the study.

\section{Consent for publication}

Not applicable.

\section{Competing interests}

The authors declare that they have no competing interests.

\section{Author details}

'Department of Medical Physiology, Institute of Health Sciences, Jimma University, 378 Jimma, Ethiopia. ${ }^{2}$ Department of Pharmacy, Institute of Health Sciences, Jimma University, 378 Jimma, Ethiopia. ${ }^{3}$ Department of Medical Microbiology, Institute of Health Sciences, Jimma University, 378 Jimma, Ethiopia. ${ }^{4}$ Department of Health Service Management, Institute of Health 
Sciences, Jimma University, 378 Jimma, Ethiopia. ${ }^{5}$ Department of Reproductive Health, Institute of Health Sciences, Jimma University, 378 Jimma, Ethiopia.

Received: 23 September 2019 Accepted: 1 July 2020

Published online: 09 July 2020

\section{References}

1. McCullough PA, Brown WW, Gannon MR, et al. Sustainable communitybased CKD screening methods employed by the National Kidney Foundation's kidney early evaluation program (KEEP). Am J Kidney Dis. 2011; 57(3 Suppl 2):S4-8

2. Gebrie MH, Ford J. Depressive symptoms and dietary non-adherence among end-stage renal disease patients undergoing hemodialysis therapy: systematic review. BMC Nephrol. 2019;20(1):429.

3. Lozano R, Naghavi M, Foreman K, et al. Global and regional mortality from 235 causes of death for 20 age groups in 1990 and 2010: a systematic analysis for the global burden of disease study 2010. Lancet. 2012;380(9859): 2095-128.

4. Meguid El Nahas A, Bello AK. Chronic kidney disease: the global challenge. Lancet. 2005;365(9456):331-40.

5. Khalil A, Abdalrahim M. Knowledge, attitudes, and practices towards prevention and early detection of chronic kidney disease. Int Nurs Rev. 2014;61(2):237-45.

6. Mohsen IM. Hypertension in developing countries: a major challenge for the future. Curr Hypertens Rep. 2018:20(5):38.

7. Wetterhall SF, Olson DR, DeStefano F, et al. Trends in diabetes and diabetic complications, 1980-1987. Diabetes Care. 1992;15(8):960-7.

8. Coresh J, Astor B, Sarnak MJ. Evidence for increased cardiovascular disease risk in patients with chronic kidney disease. Curr Opin Nephrol Hypertens. 2004;13(1):73-81.

9. Sarnak MJ, Levey AS, Schoolwerth AC, et al. Kidney disease as a risk factor for development of cardiovascular disease: a statement from the American Heart Association councils on kidney in cardiovascular disease, high blood pressure research, clinical cardiology, and epidemiology and prevention. Hypertension. 2003;42(5):1050-65.

10. Go AS, Chertow GM, Fan D, McCulloch CE, Hsu CY. Chronic kidney disease and the risks of death, cardiovascular events, and hospitalization. N Engl J Med. 2004;351(13):1296-305.

11. Anavekar NS, McMurray JJ, Velazquez EJ, et al. Relation between renal dysfunction and cardiovascular outcomes after myocardial infarction. N Engl J Med. 2004;351(13):1285-95.

12. Jafar TH, Levey AS, Jafary FH, et al. Ethnic subgroup differences in hypertension in Pakistan. J Hypertens. 2003;21(5):905-12.

13. Shera AS, Rafique G, Khwaja IA, Ara J, Baqai S, King H. Pakistan national diabetes survey: prevalence of glucose intolerance and associated factors in Shikarpur, Sindh Province. Diabet Med. 1995;12(12):1116-21.

14. Snyder S, Pendergraph B. Detection and evaluation of chronic kidney disease. Am Fam Physician. 2005;72(9):1723-32.

15. Plantinga LC, Boulware LE, Coresh J, et al. Patient awareness of chronic kidney disease: trends and predictors. Arch Intern Med. 2008;168(20):2268-75.

16. Nickolas TL, Frisch GD, Opotowsky AR, Arons R, Radhakrishnan J. Awareness of kidney disease in the US population: findings from the National Health and nutrition examination survey (NHANES) 1999 to 2000. Am J Kidney Dis. 2004:44(2):185-97.

17. Coresh J, Byrd-Holt D, Astor BC, et al. Chronic kidney disease awareness, prevalence, and trends among U.S. adults, 1999 to 2000. J Am Soc Nephrol. 2005;16(1):180-8.

18. James PA, Oparil S, Carter BL, et al. 2014 evidence-based guideline for the management of high blood pressure in adults: report from the panel members appointed to the eighth joint National Committee. JAMA. 2014; 311(5):507-20.

19. Colberg SR, Sigal RJ, Yardley JE, et al. Physical activity/exercise and diabetes: a position statement of the American Diabetes Association. Diabetes Care. 2016;39(11):2065-79.

20. Levey AS, Atkins R, Coresh J, et al. Chronic kidney disease as a global public health problem: approaches and initiatives - a position statement from kidney disease improving global outcomes. Kidney Int. 2007;72(3):247-59.

21. Levey AS, Andreoli SP, DuBose T, Provenzano R, Collins AJ. Chronic kidney disease: common, harmful and treatable--world kidney day 2007. Am J Nephrol. 2007;27(1):108-12.
22. Chin HJ, Ahn JM, Na KY, et al. The effect of the world kidney day campaign on the awareness of chronic kidney disease and the status of risk factors for cardiovascular disease and renal progression. Nephrol Dial Transplant. 2010; 25(2):413-9.

23. Vassalotti JA, Li S, Chen SC, Collins AJ. Screening populations at increased risk of CKD: the kidney early evaluation program (KEEP) and the public health problem. Am J Kidney Dis. 2009:53(3 Suppl 3):S107-14.

24. Lin CL, Chuang FR, Wu CF, Yang CT. Early referral as an independent predictor of clinical outcome in end-stage renal disease on hemodialysis and continuous ambulatory peritoneal dialysis. Ren Fail. 2004;26(5):531-7.

25. Kinchen KS, Sadler J, Fink N, et al. The timing of specialist evaluation in chronic kidney disease and mortality. Ann Intern Med. 2002;137(6):479-86.

26. Roderick $\mathrm{P}$, Jones $\mathrm{C}$, Drey $\mathrm{N}$, et al. Late referral for end-stage renal disease: a region-wide survey in the south west of England. Nephrol Dial Transplant. 2002:17(7):1252-9.

27. Jungers P, Massy ZA, Nguyen-Khoa T, et al. Longer duration of predialysis nephrological care is associated with improved long-term survival of dialysis patients. Nephrol Dial Transplant. 2001;16(12):2357-64.

28. Tamizuddin S, Ahmed W. Knowledge, attitude and practices regarding chronic kidney disease and estimated GFR in a tertiary care hospital in Pakistan. J Pak Med Assoc. 2010;60(5):342-6.

29. Boulware LE, Troll MU, Jaar BG, Myers DI, Powe NR. Identification and referral of patients with progressive CKD: a national study. Am J Kidney Dis. 2006:48(2):192-204

30. Gøransson LG, Bergrem H. Consequences of late referral of patients with end-stage renal disease. J Intern Med. 2001;250(2):154-9.

31. Choukem SP, Nchifor PK, Halle MP, et al. Knowledge of physicians on chronic kidney disease and their attitudes towards referral, in two cities of Cameroon: a cross-sectional study. BMC Res Notes. 2016;9:29.

32. Samra M, Abcar AC. False estimates of elevated creatinine. Perm J. 2012 16(2):51-2.

33. Modification of Diet in Renal Disease Study Group. The modification of diet in renal disease study: design, methods, and results from the feasibility study. Am J Kidney Dis. 1992;20(1):18-33.

34. Andreev $\mathrm{E}$, Koopman $\mathrm{M}$, Arisz L. A rise in plasma creatinine that is not a sign of renal failure: which drugs can be responsible? J Intern Med. 1999; 246(3):247-52.

35. Sakhuja V, Sud K. End-stage renal disease in India and Pakistan: burden of disease and management issues. Kidney Int Suppl. 2003:83:S115-8.

36. Mahmud M, Hussain N, Kamal A, Samoo ZI, Khan WA. Doctors' knowledge and practices regarding chronic kidney disease at a tertiary care hospital. Int Arch Med. 2016;30:9.

37. Abcar AC, Chan L, Yeoh H. What to do for the patient with minimally elevated creatinine level? Permanente J. 2004:8(1):51.

38. Luyckx VA, Tuttle KR, Garcia-Garcia G, et al. Reducing major risk factors for chronic kidney disease. Kidney Int Suppl. 2017;7(2):71-87.

39. Tuso PJ. SERVE Ethiopia. Perm J. 2009;13(3):51-64.

40. Moeller S, Gioberge S, Brown G. ESRD patients in 2001: global overview of patients, treatment modalities and development trends. Nephrol Dial Transplant. 2002;17(12):2071-6.

41. Agrawal V, Ghosh AK, Barnes MA, McCullough PA. Perception of indications for nephrology referral among internal medicine residents: a national online survey. Clin J Am Soc Nephrol. 2009;4(2):323-8.

42. Lenz O, Fornoni A. Chronic kidney disease care delivered by US family medicine and internal medicine trainees: results from an online survey. BMC Med. 2006;4:30.

43. Plantinga LC, Tuot DS, Powe NR. Awareness of chronic kidney disease among patients and providers. Adv Chronic Kidney Dis. 2010;17(3):225-36.

44. Wolide AD, Goro KK, Dibaba FK, et al. Care Provider's knowledge and attitude toward organ donation in Jimma town, Ethiopia: cross-sectional study. Transplant Proc. 2020:52(1):32-6.

45. Wolide AD, Kumela K, Kerga F, et al. Health sciences students knowledge, attitude and practices with chronic kidney disease in Jimma University, Ethiopia: a cross-sectional study. BMC Res Notes. 2019;12(1):389.

\section{Publisher's Note}

Springer Nature remains neutral with regard to jurisdictional claims in published maps and institutional affiliations. 